\title{
EFEITO DO CONGELAMENTO E DO TEMPO DE ESTOCAGEM DA POLPA DE ACEROLA SOBRE O TEOR DE CAROTENÓIDES ${ }^{1}$
}

\author{
TÂNIA DA SILVEIRA AGOSTINI-COSTA², LUCIANA NOBRE DE ABREU, L. N. ${ }^{3}$, ADROALDO GUIMARÃES \\ ROSSETTI $^{4}$
}

\begin{abstract}
RESUMO - A acerola (Malpighia glabra L.) é uma das principais fontes naturais de vitamina C e, também, excelente fonte de carotenóides. O potencial vitamínico destes pigmentos e sua possível associação com o processo de carcinogênese têm despertado grande interesse na química e estabilidade dos carotenóides em alimentos. O objetivo deste trabalho foi avaliar o efeito do processo industrial de congelamento da polpa de acerola, praticado em pequena empresa do município de Fortaleza-CE, visando à manutenção da estabilidade dos carotenóides durante a estocagem da mesma. Os carotenóides foram determinados na polpa recém-processada não congelada (controle) e nas polpas congeladas em álcool $-20^{\circ} \mathrm{C}$, estocadas por onze meses. Após quatro meses de estocagem, o conteúdo de $\beta$-caroteno da polpa congelada apresentou redução significativa de $20 \%$, em relação ao conteúdo da polpa-controle $(7,09 \mu \mathrm{g} / \mathrm{g})$, sem alteração significativa após esse período. A $\beta$-criptoxantina $(1,7 \mu \mathrm{g} / \mathrm{g}$ de polpa) foi reduzida em $37 \%$ após o primeiro mês de estocagem, mantendo estes teores estáveis até o décimo primeiro mês, quando totalizou uma perda de $62 \%$. O $\alpha$-caroteno foi encontrado em pequenas quantidades. Quanto ao potencial vitamínico, a polpa-controle apresentou $1338 \mathrm{UI} / 100 \mathrm{~g}$, correspondendo, aproximadamente, a $25 \%$ das recomendações diárias de vitamina A $/ 100 \mathrm{~g}$ de polpa para uma pessoa adulta. Este potencial foi mantido até o terceiro mês de estocagem, quando houve uma redução de $20 \%$, sem alteração significativa após este período.
\end{abstract}

Termos para indexação: acerola, carotenóides, vitamina A.

\section{EFFECT OF FREEZING AND STORING TIME OF PULP OF ACEROLA ON THE CAROTENOID CONTENTS}

\begin{abstract}
Acerola (Malpighia glabra L.) is one of the main natural sources of vitamin C and is an excellent source of carotenoids. Due to the vitamin potential of carotenoids, and their possible association with the carcinogenesis process, there is an increasing concern of the scientific community about their chemistry and stability in food. The objective of this research was to study the effect of commercial freezing and storage procedures on the carotenoid contents (in respect to the vitamin A potential) of acerola pulp. The acerola pulp was processed in a small industry in Fortaleza, CE. The carotenoid contents were determined on freshly processed pulp (control), on recently frozen pulp and over time on stored frozen pulp. The $\beta$-carotene content of the frozen pulp has decreased $20 \%$ after four months of storage, when compared to the control content $(7.09 \mu \mathrm{g} / \mathrm{g}$ ), but no significant differences existed in the subsequent months. The $\beta$-criptoxantin content $(1.7 \mu \mathrm{g} / \mathrm{g})$ decreased $37 \%$ in the first month of storage, remaining practically constant until eleventh month, when it totalized a $62 \%$ drop. The content of $\alpha$-carotene in pulp was small. About the vitamin A potential, the control pulp showed $1338 \mathrm{UI} / 100 \mathrm{~g}$, corresponding to, approximately, $25 \%$ of the daily recommendation for this vitamin. After freezing, vitamin A potential was maintained until the third month of storage, when a significant drop of $20 \%$ was observed. No significant alterations were detected in the subsequent months until the end of the evaluation period.
\end{abstract}

Index terms: acerola, carotenoids, vitamin A.

\section{INTRODUÇÃO}

O valor nutricional é um dos principais fatores que conduzem o interesse crescente no consumo de frutas. A acerola é de interesse nutricional principalmente por apresentar alto teor de ácido ascórbico. Entretanto, esta fruta é, também, importante fonte de carotenóides. Estes pigmentos naturais, tais como o $\beta$-caroteno e o licopeno, constituem uma das classes de fitoquímicos que têm recebido grande atenção nos últimos anos (Sloan, 1999 e 1996). Alguns $\beta$-carotenóides são capazes de ser convertidos em vitamina A e, como tal, desempenham um importante papel na prevenção de VADS (Vitamin A deficiency Sindrome), que causa xeroftalmia bem como distúrbios de crescimento na primeira infância (Ramalho et al. 2001).

O consumo de frutas e verduras com alto teor de carotenóides tem apresentado, também, relação inversa com o risco de desenvolvimento de câncer (Nguyen \& Schwartz, 1999; Ziegler, 1991). Estes pigmentos, como o licopeno e o $\beta$-caroteno, por exemplo, funcionam como antioxidantes naturais e têm capacidade de proteger membranas, DNA e outros constituintes celulares contra danos oxidativos (Krinsky, 1991; Krinsky, 1989; Santamaria \& Bianch, 1989).

Além do fator nutricional, a conveniência continua conduzindo forças aos desejos dos consumidores. A conveniência, quando atribuída aos alimentos, relaciona-se com a facilidade de estocagem e de preparo para o consumo doméstico (Sgarbieri, 1986). O contínuo crescimento no consumo de frutas, associado às continuas melhorias que estão sendo introduzidas na qualidade dos alimentos, indicam que as polpas congeladas de frutas tropicais devem continuar ganhando mercado. Entretanto, os consumidores estão colocando um novo padrão de conveniência nos alimentos, sendo que a qualidade e o valor nutricional devem ser preservados.

O cultivo da aceroleira é implementado hoje em nove Estados do Nordeste (Gonzaga Neto \& Soares, 1994). Pequenas e grandes empresas estão estabelecidas na região, tendo em vista o aproveitamento da acerola na produção de polpas congeladas. Em decorrência da alta instabilidade das vitaminas e pró-vitaminas, o processamento e a estocagem das frutas podem alterar significativamente a composição qualitativa e quantitativa destes nutrientes (Cavalcante, 1991; Goldman et al., 1983). A maior razão de perda dos carotenóides é a oxidação. Muitos fatores, tais como exposição à luz e ao oxigênio, tipo de matriz alimentícia, presença de enzimas, disponibilidade de água e presença de antioxidantes e/ou pró-oxidantes podem influenciar neste processo (Burton, 1989; Goldman et al., 1983).

O objetivo deste trabalho foi estudar o efeito do congelamento e do tempo de estocagem da polpa de acerola, conforme padrão de processamento comercial estabelecido em pequena empresa produtora de polpa em Fortaleza-CE, sobre o teor de carotenóides, com reflexos no potencial pró-vitamínico destes pigmentos.

\section{MATERIAL E MÉTODOS}

O processamento da polpa de acerola congelada foi conduzido em uma pequena empresa produtora de Fortaleza-CE. Após lavagem e

\footnotetext{
${ }^{1}$ (Trabalho 114/2002). Recebido: 01/07/2002. Aceito para publicação: 01/04/2003.

${ }^{2}$ Farmacêutica D. Sc. em Ciência de Alimentos, Embrapa Recursos Genéticos e Biotecnologia, C.P. 02372. CEP: 70770-900 - Brasília - DF, tania@ cenargen.embrapa.br

${ }^{3}$ Estudante de graduação em Química Industrial, UFC, estagiária da Embrapa Agroindústria Tropical, C.P. CEP: 60511-110 - Fortaleza - CE.

${ }^{4}$ Estatístico M. Sc. Embrapa Agroindústria Tropical, C.P. CEP: 60511-110 - Fortaleza - CE, adroaldo@cnpat.embrapa.br
} 
seleção das frutas, a polpa obtida (100L) foi acondicionada em PVC transparente: "polpinhas". Uma amostra aleatória controle $(2 \mathrm{~kg})$ foi separada para análise, e o restante foi congelado em álcool (-200 $\mathrm{C}$ por 10 min) e embalado (5 unidades/pacote). Outra amostra aleatória ( $15 \mathrm{~kg}) \mathrm{da}$ polpa congelada foi estocada em freezer doméstico. As determinações analíticas nas polpas recém-processadas não congeladas (controle), nas polpas recém-congeladas e nas polpas estocadas durante onze meses foram feitas com três repetições. As polpas não foram analisadas após o décimo segundo mês de estocagem, devido ao descongelamento das mesmas, causado por longa queda de tensão elétrica nesse período. Em cada repetição, foram empregados $300 \mathrm{~g}$ de amostra acrescida de antioxidante butil hidroxitolueno (BHT). O ambiente foi mantido com baixa luminosidade e temperatura (cerca de $21^{\circ} \mathrm{C}$ ).

Os carotenóides extraídos em acetona foram saponificados com $\mathrm{KOH} 10 \%$ em metanol e separados em coluna de MgO:hyflosupercel, conforme Rodriguez-Amaya et al. (1976). Os isômeros do $\beta$-caroteno foram separados em coluna de $\mathrm{Ca}(\mathrm{OH})_{2}$ A identificação foi feita, considerando-se a ordem de eluição na coluna cromatográfica, os espectros de absorção na região do visível $(350-550 \mathrm{~nm})$, os valores de RF na camada de sílica gel e as reações químicas específicas: acetilação, metilação e isomerização cis-trans (Davies, 1976). A quantificação de cada fração foi realizada a partir das respectivas absorvâncias máximas, aplicando-se a lei de Beer. Os valores das absortividades foram tabelados por Davies (1976). O valor de vitamina A foi calculado a partir da atividade pró-vitamínica de cada carotenóide precursor, tabelada por Bauernfeind (1972).

As antocianinas foram determinadas por diferença de absorvância a $500 \mathrm{~nm}$, após diluição do suco em tampões pH 0,5 e pH 4,7, conforme Fuleki \& Francis (1968).

\section{RESULTADOS E DISCUSSÃO}

Na polpa de acerola recém-processada não congelada (controle), foram identificados $\beta$-caroteno ( $7,1 \mu \mathrm{g} / \mathrm{g}$ de polpa), $\beta$-criptoxantina (1,7 $\mu \mathrm{g} / \mathrm{g}$ de polpa) e $\alpha$-caroteno $(0,2 \mu \mathrm{g} / \mathrm{g}$ de polpa). Cavalcante (1991) encontrou fitoflueno e $\alpha$-caroteno (traços), $\beta$-caroteno $(4,0-25,8 \mu \mathrm{g} / \mathrm{g}) \mathrm{e}$ $\beta$-criptoxantina $(0,5-3,6 \mu \mathrm{g} / \mathrm{g})$ em amostras de acerola in natura obtidas em mercados públicos de três Estados do Brasil. O fitoflueno não foi considerado neste trabalho por ser destituído de cor e de atividade vitamínica, além de estar presente em pequenas quantidades. Os demais carotenóides da polpa de acerola apresentaram resultados mais próximos dos valores encontrados para as acerolas in natura do Estado de São Paulo do que para as amostras do Ceará e Pernambuco. Estas variações podem estar associadas a fatores, tais como safras, localidades de colheita e variedades, embora os valores aqui registrados estejam dentro da faixa encontrada para frutos in natura.

Não foram detectados isômeros cis do $\beta$-caroteno nas polpas de acerola não congeladas (controle), indicando que a homogeneização da polpa não alterou significativamente a forma do $\beta$-caroteno presente naturalmente no fruto. Entretanto, foram detectados 4,5\% de 9 -cis-, $6,5 \%$ de 13 -cis- e $89 \%$ de trans- $\beta$-caroteno no terceiro mês de estocagem da polpa congelada, embora, neste período, o congelamento não tenha apresentado efeito significativo sobre o teor total de? $\beta$-caroteno. Já no quarto mês de estocagem, o conteúdo total deste carotenóide apresentou redução significativa de $20 \%$, em nível de 0,05 de probabilidade, pelo teste de Tukey, em relação à polpa-controle (Figura 1). A perda total no décimo primeiro mês de congelamento foi de $26 \%$.

Cavalcante (1991) avaliou a estabilidade dos carotenóides na polpa de pitanga após o congelamento lento (6h) e estocagem por 90 dias. Neste caso, a estocagem por 30 dias acarretou perda significativa de $63 \%$ de $\beta$-caroteno, sem alteração significativa após esse período. O processamento da acerola atualmente praticado em algumas pequenas indústrias do Nordeste (congelamento através de imersão em álcool a $20^{\circ} \mathrm{C}$, por $10 \mathrm{~min}$ ) pode ter sido importante no aumento da estabilidade do $\beta$-caroteno durante a estocagem da polpa congelada de acerola. Entretanto, características inerentes à composição da fruta em questão, tais como pH e presença de enzimas (Cavalcante 1991), também podem ter interferido na estabilidade deste pigmento.

O teor de $\beta$-criptoxantina da polpa congelada de acerola, em relação à polpa-controle, foi reduzido significativamente em $37 \%$ no primeiro mês de estocagem (Figura 1). No décimo primeiro mês de estocagem, houve uma segunda redução significativa no teor de $\beta$-criptoxantina, que apresentou uma perda total de $61 \%$ em relação à polpa-controle. Comportamento semelhante foi observado com a polpa congelada de pitanga, que apresentou redução de $38 \%$ no teor deste carotenóide após a estocagem da polpa por 30 dias, sem alteração significativa até o terceiro mês de estocagem, quando o experimento foi encerrado (Cavalcante, 1991).

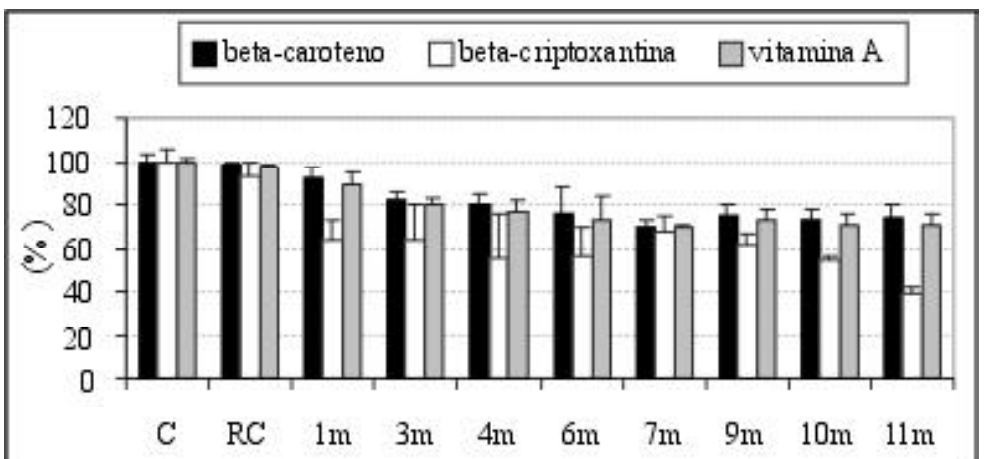

FIGURA 1 - Estabilidade do $\beta$-caroteno, da $\beta$-criptoxantina e da vitamina A após o congelamento e estocagem da polpa de acerola. C: polpa não congelada (controle); RC: polpa recémcongelada; $1 \mathrm{~m} . . .11 \mathrm{~m}$ : polpas estocadas por períodos de $1 \mathrm{a}$ 11 meses. Cada resultado é média e desvio-padrão de 3 repetições.

O teor de $\alpha$-caroteno da polpa de acerola variou entre 0,11 e $0,20 \mu \mathrm{g} / \mathrm{g}$ após o congelamento e estocagem. Durante este período, não foi encontrada nenhuma diferença significativa nos baixos teores detectados deste carotenóide.

Quanto ao potencial vitamínico, a polpa não congelada de acerola (controle) apresentou $1338 \mathrm{UI} / 100 \mathrm{~g}$ de polpa, ou seja, cerca de $25 \%$ das necessidades diárias de vitamina A para uma pessoa adulta. Este potencial pode variar em função da variedade e da procedência da fruta in natura empregada no processamento. Cavalcante (1991) encontrou valores de vitamina A que variaram entre 720 a 4540 UI/100g de acerolas in natura obtidas nos Estados de São Paulo e Pernambuco, respectivamente.

O valor de vitamina A da polpa congelada de acerola, no terceiro mês de estocagem, apresentou redução significativa de $20 \%$, em nível de 0,05 de probabilidade, pelo teste de Tukey, em relação à polpacontrole (Figura 1). A perda no décimo primeiro mês de estocagem foi de $30 \%$. Na polpa congelada de pitanga, Cavalcante (1991) verificou-se uma perda substancialmente mais elevada: $50 \%$ no terceiro mês de estocagem, quando o estudo foi finalizado. O efeito foi causado, principalmente, pela alta instabilidade do $\beta$-caroteno na polpa de pitanga.

Na polpa de acerola, a instabilidade da $\beta$-criptoxantina foi maior em relação à instabilidade do $\beta$-caroteno. Mas, as perdas de $\beta$ criptoxantina, no terceiro e no décimo primeiro meses de estocagem da polpa, não afetaram significativamente o potencial vitamínico, pois a contribuição deste carotenóide neste potencial foi de apenas 11\%. A $\beta$ criptoxantina apresenta menor capacidade de conversão em vitamina $\mathrm{A}$ em relação ao $\beta$-caroteno, que possui $100 \%$ de atividade vitamínica e contribuiu com $88 \%$ do potencial vitamínico da polpa. As pequenas quantidades de $\alpha$-caroteno responderam apenas por $1 \%$ do potencial.

Além de pró-vitaminas, os carotenóides são, também, pigmentos responsáveis pela cor de muitas frutas, tais como a laranja, a goiaba e a melancia. Entretanto, na acerola, a coloração amarela conferida pelos carotenóides é mascarada pela presença de antocianinas vermelhas. A estocagem da polpa congelada não branqueada de acerola apresenta 
descoloração esporádica, tornando-se amarela. Esta despigmentação acarreta prejuízos na comercialização da polpa. O monitoramento químico do teor de antocianinas acusou redução significativa de $9 \%$ no teor deste pigmento após o congelamento da polpa por nove meses. A perda acumulada de antocianina após congelamento da polpa por 12 meses foi de 14\% (Figura 2). Entretanto, neste material, não foi observada nenhuma despigmentação visual.

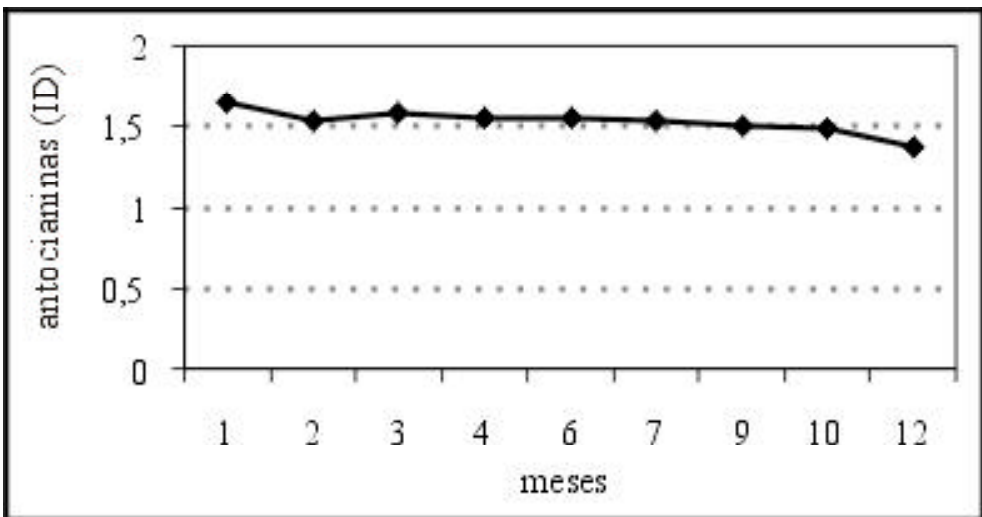

FIGURA 2 - Perdas de antocianinas durante a estocagem da polpa congelada de acerola. ID: índice de degradação.

\section{CONCLUSÕES}

A polpa de acerola apresentou uma retenção relativamente boa dos carotenóides pró-vitamínicos após o congelamento e a estocagem por um período de 11 meses, conforme procedimento comercial praticado em algumas pequenas indústrias do Nordeste do Brasil. Ao que parece, o congelamento rápido por imersão em álcool foi importante para preservar a estabilidade do $\beta$-caroteno na polpa congelada de acerola. Entretanto, este resultado pode ter sido conseqüência de algumas características inerentes à acerola, como pH reduzido e suposta ausência de enzimas. A influência do branqueamento da polpa, visando à inativação de enzimas, e o efeito do congelamento rápido em nitrogênio líquido poderão ser testados em trabalhos futuros, visando a aumentar a preservação destes pigmentos em polpas congeladas de frutas tropicais variadas.

\section{REFERÊNCIAS BIBLIOGRÁFICAS}

BAUERNFEIND, J. C. Carotenoid vitamin A precursors and analogs in foods and feeds. Journal of Agricultural and Food Chemistry, Columbus, v.20, n.3, p.456-473, 1972.

BURTON, G. W. Antioxidant action of carotenoids. The Journal of Nu- trition, Bethesda, v.119, p.109-111, 1989.

CAVALCANTE, M. L.Composição de carotenóides e valor de vitamina A em pitanga (Eugenia uniflora) e acerola (Malphighia glabra L.). 1991. 87p. Dissertação (Mestrado em Ciência de Alimentos) - Faculdade de Engenharia de alimentos, Universidade Estadual de Campinas, Campinas, 1991.

DAVIES, B. H. Carotenoids. In: Goodwin, T. W. (Ed.). Chemistry and biochemistry of plant pigments. London: Academic Press, 1976. p.38165 .

FULEKI, T.; FRANCIS, J. Quantitative methods for anthocyanins. 2. Determination of total anthocyanin and degradation index for cranberry juice. Journal of Food Science, Chicago, v.33, p.78-83, 1968.

GOLDMAN, M.; HOREV, B.; SAGUY, I. Decolorization of $\beta$-carotene in model systems simulating dehydrated foods: mechanism and kinetic principles. Journal of Food Science, Chicago, v. 48, p.751-754, 1983.

GONZAGA NETO, L.; SOARES, J. M. Acerola para exportação: aspectos técnicos da produção. Brasília: Embrapa-SPI, 1994, 43p. (Série Publicações Técnicas FRUPEX, 10).

KRINSKY, N. I. Carotenoids as chemopreventive agents. Preventive Medicine, San Diego, v.18, p.592-602, 1989.

KRINSKY, N. I. Effects of carotenoids in cellular and animal systems. American Journal of Clinical Nutrition, Davis, v. 53, p.238S-246S, 1991.

NGUYEN, M. L.; SCHWARTZ, S. J. Lycopene: chemical and biological properties. Food Technology, Chicago, v. 53, n.2, p.38-45, 1999.

RAMALHO, R.A.; ANJOS L.A.; FLORES H. Valores séricos de vitamina A e teste terapêutico em pré-escolares atendidos em uma unidade de saúde do Rio de Janeiro, Brasil. Revista de Nutrição, v.14, p.5-12, 2001.

RODRIGUEZ-AMAYA, D.B.; RAYMUNDO, L. C.; LEE, T. C.; SIMPSON, K. L.; CHICHESTER, C. O. Carotenoids pigments changes in ripening Mormodica charantia. Annals of Bothany, San Diego, v. 40, p. 615-624,1976.

SANTAMARIA, L.; BIANCH, A. Cancer chemoprevention by suplemental carotenoids in animals and humans. Preventive Medicine, San Diego, v.18, p.603-623, 1989.

SGARBIERI, V. C. Nutrição e tecnologia de alimentos. Boletim da Sociedade Brasileira de Ciência e Tecnologia de Alimentos, Campinas, v. 20, p.115-139, 1986.

SLOAN, A. E. Top ten trends to watch and work on for the millennium. Food Technology, Chicago, v.53, n.8, p.40-53, 1999.

SLOAN, A. E. America's appetite 96: the top 10 trends to watch and work on. Food Technology, Chicago, v. 50, n.7, p.55-71, 1996.

ZIEGLER, R. G. Vegetables, fruits, and carotenoids and the risk of cancer. American Journal of Clinical Nutrition, Davis, v.53, p.251S-259S, 1991. 